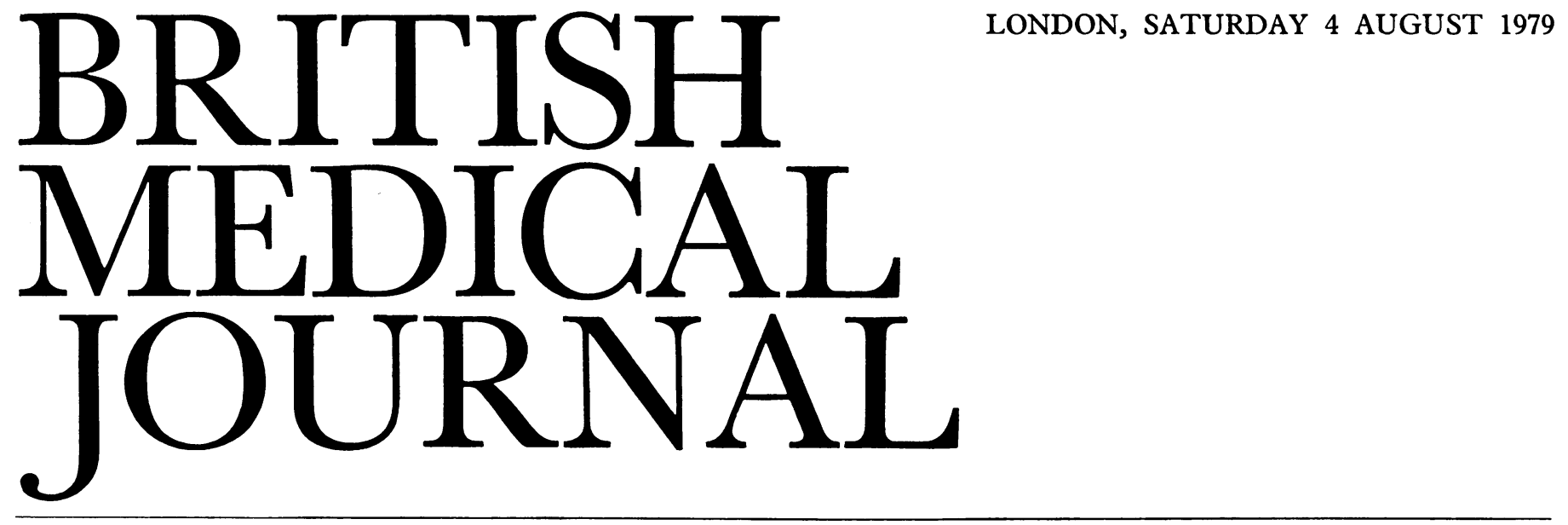

Wernicke's encephalopathy is one of the non-infective neurological disorders that are reversible, at least in the early stages, with specific treatment; yet all too often it is not diagnosed during the patient's lifetime. Wernicke described his three cases in 1881, and not long afterwards the characteristic changes in the brain became accepted as a neuropathological entity. Though the condition was usually associated with alcoholism, it was also recognised in non-alcoholics with nutritional deficiency, particularly when due to gastrointestinal disease. ${ }^{12}$ In parallel with further study of the pathological and clinical features ${ }^{3}{ }^{4}$ came the results of research showing that the disorder was due to thiamine deficiency. ${ }^{5-8}$ The remarkable response to parenteral thiamine was reported in malnourished prisoners during the second world war, ${ }^{9}$ and little needs to be added even now to Spillane's masterly review. ${ }^{10}$

Alcoholism is now a growing problem in most Western countries, yet many cases of Wernicke's encephalopathy are still being missed. In Perth, Australia, Harper ${ }^{11}$ found that only seven cases had been diagnosed during life out of 51 at necropsy. Wernicke's encephalopathy accounted for $1.7 \%$ of all neuropathological necropsies there between the years 1973 and 1976 , so that Harper's conclusion that it is more common than is generally realised seems justified. The condition has to be looked for specifically at necropsy, since the diagnosis can be established in some cases only by histological examination of the brain. In Harper's series ${ }^{11}$ the mamillary bodies were almost invariably affected yet did not appear macroscopically abnormal in 19 out of his 51 cases. Diagnosis needs to be made early, however, for treatment to be effective: last year Wallis et al $^{12}$ reported from New Zealand four comatose patients with the Wernicke-Korsakoff syndrome, three of whom died. A similar fate befell the case presented at the clinicopathological conference held recently at the Royal College of Physicians of London as reported in the BMF (30 June 1979, p 1768).

What can we do to reduce this mortality? A history of alcoholism, previous or associated signs of alcoholic neurological disease, or any condition causing a poor nutritional state should alert the physician. We should not expect or wait for the classical triad of clouding of consciousness, ophthalmoplegia, and ataxia described by Wernicke. This is neither constant nor frequent, and the diagnosis needs to be suspected at the bedside in any confused or stuporous patient with history of headache, anorexia, vomiting, or loss of vision and with either excitement or depression. Some patients show features of Korsakoff's syndrome, with impairment of shortterm memory and confabulation ${ }^{3}$ while retaining memory for past events. Disorientation in time and space may lead to delirium and coma with no focal cerebral signs, intact pupillary light reactions, and absent doll's eye and caloric responses. These, however, are serious signs; the early signs -memory impairment, ocular palsies, nystagmus, and truncal ataxia-will be recognised only in patients sufficiently accessible for testing. Minor episodes with various combinations of these symptoms often recur before catastrophic changes become irreversible.

The more severe and long lasting the mental disturbance and impairment of consciousness, the less likely will the response to treatment be rapid and complete. The lesson is clear-any combination of suspicious symptoms and signs calls for urgent treatment with intravenous thiamine whether or not a history of alcoholism is obtained and especially in cases of chronic diarrhoea, hyperemesis, or known nutritional and gastrointestinal disease. Parenteral injections of B-complex vitamins should also be given in view of the possibility of multiple deficiencies.

Since the onset of Wernicke's encephalopathy may be acute, subacute, or chronic, the differential diagnosis includes encephalitis and other amnesic and psychotic syndromes due to metabolic deficiencies and toxic conditions as well as multiple sclerosis, brain stem and other intracranial tumours, and neurosyphilis. Meningeal infiltration secondary to a primary carcinoma of the stomach may mimic Wernicke's encephalopathy. Another treatable complication of alcoholism is chronic subdural haematoma, which may be bilateral. Ventricular enlargement and cerebellar atrophy are also associated with alcoholism ${ }^{\mathbf{1 4}}$; their recognition on CT scanning ${ }^{15}$ may help exclude a space-occupying lesion.

Among the occasional complications are epilepsy, hypothermia, and inappropriate secretion of $\mathrm{ADH} .{ }^{13}$ The blood transketolase and pyruvate concentrations may confirm the thiamine deficiency, but there is no value in waiting for these results. Hypoglycaemia must be detected and treated, but intravenous or nasogastric tube feeding must not be started without vitamin supplements-a glucose load may be the last straw for the exhausted stores of thiamine, and so may 
precipitate coma and sudden death, as in the cases reported by Wallis et al. ${ }^{12}$

While the early signs are still reversible, the damage may be biochemical and invisible. Nevertheless, typically at necropsy there are focal neuronal lesions with congestion and haemorrhages in the medial parts of the thalamus, the hypothalamus, hippocampus, mamillary bodies, and periaqueductal grey matter in the mid-brain. These lesions may extend to the floor of the 4th ventricle and vagal nuclei, causing terminal hypotension and respiratory failure. Their characteristic focal distribution may indicate the parts which are most sensitive to the deficiency, particularly as transketolase, a thiaminedependent enzyme, loses its activity in the pontine tegmentum more rapidly than in other areas.

The important messages, then, are that the WernickeKorsakoff syndrome is preventable, can be diagnosed during life, and treatment with thiamine is most effective in the early stages. The condition is more common than generally realised and should be suspected and treated more often than hitherto; but would it not be better still-as Victor $e t$ al ${ }^{14}$ concluded in 1971-to intensify public health measures for the control of alcoholism and, possibly, to fortify foodstuffs with thiamine?

1 Neuburger, K, Virchows Archiv für pathologische Anatomie und Physiologie, 1936, 298, 68 .

2 Riggs, H E, and Boles, R S, Quarterly fournal of Studies on Alcohol, 1944, 5, 361 .

3 Campbell, A C P, and Biggart, J H, Fournal of Pathology and Bacteriology, $1939,48,245$.

1 Campbell, A C P, and Russell, W R, Quarterly Fournal of Medicine, $1941,10 \mathrm{NS}, 41$.

S Peters, R A, Lancet, 1936, 1, 1161.

- Zimmerman, H M, Yale Journal of Biology and Medicine, 1939, 12, 23.

7 Alexander, L, American fournal of Pathology, 1940, 16, 61.

- Ferraro, A, and Roizin, L, Transactions of the American Neurological Association, 1941, 67, 177.

9 de Wardener, H E, and Lennox, B, Lancet, 1947, 1, 11.

19 Spillane, J D, Nutritional Disorders of the Nervous System, Chapter 5. Edinburgh, Livingstone, 1947.

11 Harper, C, Fournal of Neurology, Neurosurgery, and Psychiatry, 1979, 42, 226.

12 Wallis, W E, Willoughby, E, and Baker, P, Lancet, 1978, 2, 400.

13 Ebels, E J, Lancet, 1978, 2, 781.

14 Victor, M, Adams, R D, and Collins, G H, The Wernicke-Korsakoff Syndrome. Oxford, Blackwell Scientific, 1971.

15 Cala, L A, et al, Australian and New Zealand fournal of Medicine, 1978, 8, 147.

\section{Pesticidal diabetes}

Man's success in the rat race of evolution has depended in part on his manipulation of the environment to his own advantage; and in an age when he has put mice into space the devastation caused by rodent-transmitted epidemics is easily forgotten. The Black Death (1348), for instance, killed one in three of the population in England, who, despite having heard of its westerly progression through Europe, were defenceless against the plague.

Rats occupy only one part of the arena of environmental medicine, but the emergence of "super-rats," resistant to the poison warfarin, caused considerable alarm. Among the toxic agents developed as an answer was - $\mathrm{N}$-3-pyridylmethyl $\mathrm{N}$-p-nitrophenyl (PNU), introduced into the United States in July 1975. The LD50 had been shown to be $4.75 \mathrm{mg} / \mathrm{kg}$ for rats, $710 \mathrm{mg} / \mathrm{kg}$ for chickens, and $2000-4000 \mathrm{mg} / \mathrm{kg}$ for rhesus monkeys, with little or no secondary toxicity in cats and dogs. ${ }^{1}$ These figures suggested that "non-target animals," including man, should be relatively safe, but hopes were dashed by seven human deaths due to accidental ingestion of contaminated rice in Korea. ${ }^{2}$ In 18 recorded poisonings in the United States there were five deaths, attributed to diabetic ketoacidosis, intestinal perforations, cardiac arrhythmias, and pneumonitis. ${ }^{3}$ Some children treated promptly with gastric lavage recovered without sequelae, ${ }^{3}$ but in most cases survivors have developed ketosis-prone diabetes mellitus and severe autonomic neuropathy. ${ }^{4}$

Early symptoms of poisoning with PNU include nausea, vomiting, abdominal pain, mental confusion, chest pain, dysphagia, cardiac arrhythmias, and pneumonitis. ${ }^{4}$ Severe orthostatic hypotension, loss of bladder reflexes, and peripheral polyneuropathy occur later. ${ }^{5}$ Serum amylase concentrations have been reported to be raised. ${ }^{45}$ The diabetic hyperglycaemia may remit for a short period and so be missed. ${ }^{4}$

The chemical structure of PNU is not unlike that of streptozotocin and alloxan, both of which are used to induce diabetes in animal studies. Streptozotocin depresses nicotinamide-adenine dinucleotide, and nicotinamide (niacinamide) has been shown to protect animals against its diabetogenic effect if administered before or even up to two hours after the poison. ${ }^{6}$ This protection also occurs in animals given PNU, provided the nicotinamide is given within an hour of intoxication. $^{7}$

Rationally, therefore, nicotinamide should act as a specific antidote in poisoning with $\mathrm{PNU}-$ in conjunction with gastric lavage and symptomatic treatment of the diabetes, arrhythmias, and pneumonitis. The dose of nicotinamide is, however, still uncertain. One patient (weighing $70 \mathrm{~kg}$ ) given $500 \mathrm{mg}$ six hourly showed no signs of liver damage even after several weeks. ${ }^{3}$ Doses of $3.0 \mathrm{~g}$ have been given intravenously over 24 hours to patients with acute pellagra without undue effects, though in one case liver damage occurred in a patient who had taken $3.0 \mathrm{~g}$ daily for 18 months. ${ }^{8}$ An initial dosage of $3.0 \mathrm{~g}$ by intravenous infusion over the first 24 hours followed by $500 \mathrm{mg}$ six hourly seems reasonable and relatively safe, even though this is considerably less than the $250-500 \mathrm{mg} / \mathrm{kg}$ needed in rats to inhibit the diabetogenic action of streptozotocin given at a dose of $50 \mathrm{mg} / \mathrm{kg} .{ }^{9}$ Pending further studies, we do not know how long such treatment should be given. Nicotinic acid has also been tried as an antidote, ${ }^{4}$ but since it is more toxic in man, ${ }^{810}$ and in animals protects only against alloxan and not streptozotocin, ${ }^{11}$ its routine use cannot be recommended.

The neurological effects of poisoning with PNU are of great theoretical interest. Claude Bernard's observations of diabetes after puncture of the fourth cerebral ventricle have been followed by the discovery that acetylcholine stimulates the secretion of insulin, and conversely that increased sympathetic activity or electrical stimulation of the ventromedial hypothalamic nucleus increases the secretion of glucagon and exacerbates any tendency to diabetes. ${ }^{12}$ Now a single compound has been found to cause both severe autonomic neuropathy and diabetes, possibly by the reduction in concentrations of nicotinamide-adenine dinucleotide in the brain $^{13}$ and pancreas. ${ }^{14}$ Might this be the link between the brain and diabetes? Could the patient described by Miller $e t a l$, who produced C-peptide in response to arginine, ${ }^{3}$ have simply lost a compensatory neurological drive to those beta cells which survived the poisoning, and thereby have developed overt diabetes?

1 Peardon, D L, Pest Control, 1974, 42, 14, 16, 18, 27.

${ }^{2}$ Chemical Engineering News, 1975, 53, 8.

${ }^{3}$ Miller, L V, Stokes, J D, and Silpipat, C, Diabetes Care, 1978, 1, 73.

4 Pont, A, et al, Archives of Internal Medicine, 1979, 139, 185.

5 Prosser, P R, and Karam, J H, Fournal of the American Medical Association, 1978, 239, 1148. 